\title{
Significant progress in transport geography in China
}

\author{
WANG Chengjin, JIN Fengjun \\ Institute of Geographic Sciences and Natural Resources Research, CAS, Beijing 100101, China
}

Transport geography is a major branch of economic geography. It aims to study the spatial pattern of transport infrastructure along with the transport network, traffic organization, and passenger and cargo flow along with their evolution. Research on modern transport geography began in the early 20th century. During the last 100 years, important advances in transport geography have been achieved, and development in this field in China has kept pace with the rest of the world. Our predecessors have completed many fruitful and pioneering works in both theory and practice. In the leap-forward development phase of the transport industry over the past thirty years and particularly since the beginning of the 21 st century, many issues related to the transport network in China have become the focal points of research in various fields. Building on this background, researchers at the Institute of Geographic Sciences and Natural Resources Research, Chinese Academy of Sciences, studied the theoretical and practical issues of transport geography from the thematic and synthetic perspectives, characterized the spatial regularity of transport infrastructure, and described its relationship with the spatial organization of the social-economic system. Based on the results, the Series of Transport Geography and Regional Development was compiled and published.

\section{Organization and characteristics of series}

Series of Transport Geography and Regional Development was designed and organized by the workshop of transport geography at the Institute of Geographic Sciences and Natural Resources Research, Chinese Academy of Sciences. This workshop involves three generations of researchers including Zhang Wenchang, Jin Fengjun, Wang Chengjin and Wang Jiao'e, graduate students, postdocs, and visiting scholars. They began the research for this series in 2005, and five books have been published as of 2014 .

This series of books is organized as follows. (i) A two-level structure composed of comprehensive research and thematic research was developed following the traditional path of study in transport geography. Two books provided by JIN Fengjun were organized from the perspective of comprehensive research, while three other books presented by Wang Chengjin and Mo Huihui were written mainly from the perspective of thematic research. (ii) The authors paid attention not only to the theoretical analysis and construction of transport geography, but also to empirical research and case analyses. (iii) Regarding the traditional aspects of transport geography, such as distribution, organization, and regularities of the transport network, this series focused on the spatial mechanism of transport construction and traffic organization. In particular, the authors 
probed the various spatial effects of transport construction and the relationships between transport construction and regional development along with social-economic factors such as population, city, and resource development. (iv) This series involved the studies of wider spatial scales and attached great importance to innovative methodologies and techniques. The authors not only provided studies on national and worldwide transport networks, but also studied transport construction and organization in metropolitan regions, even in the urban block. Many theories and methodologies of transport histology, corporation geography, complex networks, and GIS were applied. (v) Interestingly, in addition to the systematic analyses of theory and methodology, the authors discussed the hot issues in transport construction and regional development and revealed the development mechanism and the coupling relationship of transport construction and regional development.

Table 1 Publication of transport geography and regional development series

\begin{tabular}{|c|c|c|c|c|}
\hline Name of book & Author & Publisher & Year-month & $\begin{array}{l}\text { Word count/ } \\
1000 \text { words }\end{array}$ \\
\hline $\begin{array}{l}\text { Infrastructure and Spatial Organization of } \\
\text { the Social-economic System }\end{array}$ & Jin Fengjun & Science Press & $2012 / 01$ & 440 \\
\hline $\begin{array}{l}\text { Evolution and Developing Mechanism } \\
\text { of Container Port Network }\end{array}$ & Wang Chengjin & Science Press & $2012 / 09$ & 435 \\
\hline $\begin{array}{l}\text { Organization Mechanism of Functional } \\
\text { Area and Spatial Welfare }\end{array}$ & Jin Fengjun & Science Press & $2013 / 06$ & 440 \\
\hline $\begin{array}{l}\text { Spatial Mode and Organization Mecha- } \\
\text { nism of Logistics Corporation Network }\end{array}$ & Wang Chengjin & Science Press & $2014 / 08$ & 460 \\
\hline $\begin{array}{l}\text { Complex Transport Network: Structure, } \\
\text { Evolution and Mechanism }\end{array}$ & $\begin{array}{l}\text { Mo Huihui, } \\
\text { Wang Jiao'e }\end{array}$ & $\begin{array}{c}\text { Economy \& } \\
\text { Management Press }\end{array}$ & $2012 / 08$ & 300 \\
\hline
\end{tabular}

\section{Major research and achievements}

The main contents of this series are described below.

Infrastructure and Spatial Organization of the Social-economic System systemically discussed the scope and development regularities of infrastructures and their role in the construction of the social-economic system. This book also analyzed the criteria of infrastructure construction and evaluated the spatial effect methodology. Furthermore, it examined the development mechanism of the infrastructure system and determined the effect of the mechanism on the spatial organization and evolution of the social-economic system based on efficient land development.

The book Organization Mechanism of Functional Area and Spatial Welfare demonstrated the spatial mechanism and mode of human activities based on the construction of functional region and evaluated the spatial welfare of different modes and factors of the functional region, such as safety, health, and development. The author attached importance to the conception, value, and function of social-economic organization and chose the functional regions such as compact cities, transit-oriented development, and metropolitan zones to analyze the function, efficiency, and spatial welfare. Furthermore, the author chose motorization, informatization, and constructive strategy to discuss the function and efficiency of spatial organization and their effects on the spatial structure and spatial welfare.

In Evolution and Developing Mechanism of Container Port Network, the author described the development process of the global container port system and examined the evolving regularities. Furthermore, Professor Wang analyzed the spatial organization of the global shipping network and revealed the development mechanism of the hub port; in particular, he probed the influence 
of new factors on port development. He also presented a detailed discussion of the spatial structure, evolution, and mode of container ports in China along with their differences at the national and regional scales.

The book Complex Transport Network: Structure, Evolution and Mechanism systematically reviewed the conception, theoretical basis, and methodology of the complex transport network. The author constructed a new category system for the transport network. In particular, railways, aviation, and expressways were chosen to discuss the statistical characteristics, evolution, and mechanism of the transport network with the help of the methodology of graph and complex network.

The book Spatial Mode and Organization Mechanism of Logistics Corporation Network provided many geographical regularities of the logistics corporation network at various spatial scales and the spatial mechanism. Moreover, the author analyzed the spatial issues of distribution, location selection, agglomeration, spatial network, and spatial operation for the logistics corporation and proposed the common hub-and-spoke system mode. The author also discussed the global expansion of the logistics corporation network and proposed the spatial mode of the regional logistics network.

\section{Future planning and research focus}

Based on the long-term research plan, this group will continue to pursue theoretical, methodological, and applied research based on "Transport Geography and Regional Development." The group will also identify several topics according to the latest demand for social-economic development and complete about four or five new books in the coming two to four years. Finally, this group will strive to complete about 10 books.

(i) Since the 1990s, a large number of expressways, high-speed railways, and intercity rail transits have been constructed. This infrastructure has rapidly expanded the high-speed transport network in China. The high-speed transport network has not only increased the transport infrastructure and the effect of spatial-temporal convergence, but also produced an unprecedented influence on resident travel, cargo flow, and energy security. Based on this topic, the group will publish the book Spatial Mode of High-speed Transport Network and Spatial Effect.

(ii) Generally, a port is the gateway for regional development, and its functional structure is a miniature of industrial structure in the hinterland. The new round of development in the heavy chemical industry since the 1990s deepened the differentiation of functional structure for the port. Based on this topic, this group will publish the book Spatial Mode between Port Function and Hinterland Industry.

(iii) The airport is a large infrastructure for a region. With the increase in resident travel, resource development, and tourism activities, China has entered a phase of rapid airport construction. Therefore, the rational distribution of feeder airports and the organization of an aviation network have become important issues. A new book entitled Theoretical Mode of Airport Distribution and Aviation Network Organization and Empirical Study will be published on this topic.

(iv) With the implementation of a new pattern of urbanization, the population will continue to be concentrated in cities and/or urban agglomerations (their surrounding areas). The interconnection of the transport network, the sharing of large infrastructure, and the construction of a logistics hub will become important topics in regional development and urban management. Accordingly, the book Spatial Pattern and Mechanism of Transport Network in Urban Regions will be published in the next two to three years. 